\title{
Enhancing the process of medical products users' identification: proposal of the Users Broadening Map method
}

\author{
Carina Campese * and Janaina Mascarenhas
}

Production Engineering Department, University of Sao Paulo - USP, São Carlos, Brazil. Av. Trabalhador São Carlense, 400, São Carlos - SP - Brazil, 13566-590.

World Journal of Advanced Engineering Technology and Sciences, 2021, 03(02), 050-064

Publication history: Received on 19 September 2021; revised on 28 October 2021; accepted on 30 October 2021

Article DOI: https://doi.org/10.30574/wjaets.2021.3.2.0071

\begin{abstract}
The Medical Equipment (ME) market has grown worldwide. As with any product development, ME should be developed based on the needs of its users and the search for good usability. User-Centered Design methods can help in identifying such needs and in the search for usability in products. Although many methods are suggested, there is a shortage of methods to raise users of a particular product. Thus, this work aims to develop a method to identify users of medical products. The method developed (users broadening map) was applied in a focus group and three case studies, and many benefits were identified. The users broadening map brings a better understanding of what a user is, facilitates the identification of different users, helps in prioritizing requirements, and in selecting users for tests. In addition, the information obtained by the method application can be used by companies to carry out reports for usability certification.
\end{abstract}

Keywords: Usability method; User centered design; Product development process; Usability standard; Medical devices

\section{Introduction}

The medical equipment market is world-class and has rapid growth [1]. In 2008, the world market for this equipment was valued at US \$ 210 billion [2]. Ten years later, this market was already worth almost $\$ 423.8$ billion, and the forecast for 2020 is that it will grow to $\$ 521.64$ billion [3].

The medical products industry in Brazil has also expanded over the years. In 2018, the country ranked fifth in the most attractive market in the region of the Americas for the sale of medical devices [4], registering an increase of $13.5 \%$ and moving US $\$ 10.5$ billion [5]. It is an innovative and intensely competitive industry, characterized by easy access to technology through partnerships between companies and universities, non-profit organizations, scientists, engineers, and qualified technicians [1].

Product development usually starts with the discovery of a market need, and then solutions are developed to meet that need [6]. In the Product Development Process (PDP), companies follow phases of strategic planning and need assessment, concept development, detailing, checks and validations, preparation for production, manufacture, sales, and product monitoring in the market $[7,8]$.

In product development, and especially in the development of medical products, it is essential to ensure that the initial need has been understood and met [9]. To do this, the generation of concepts must be based on user requirements [10],

\footnotetext{
${ }^{*}$ Corresponding author: Carina Campese

Production Engineering Department, University of Sao Paulo - USP, São Carlos, Brazil. Av. Trabalhador São Carlense, 400, São Carlos - SP - Brazil, 13566-590. 
therefore, the user must be involved in product development. User involvement, in turn, is an essential element of the User-Centered Design (UCD) theory [11], which has as one of its goals to increase the usability of the products developed $[12,13]$.

Usability is the ability of a system to meet the user's needs and it is related to how well the user can perform the functionality of a system [14]. The usability of a product can be assessed on four aspects [15]: effectiveness (accuracy and integrity with which users achieve their goals, accessing the correct information or generating the expected result), efficiency (resources that users spend on reaching their goals), satisfaction (comfort and acceptability of the product), and context of use (physical and social environment in which the product is used).

Poor usability of medical products can lead to serious accidents. Errors due to the use of this equipment are a common cause of injuries and even deaths of patients [16]. A survey conducted in 2013 indicates that 25\% of medical errors during surgery are caused by problems related to technology or some equipment [17]. And these numbers tend to increase: in 2015, the ECRI Institute pointed out that approximately $70 \%$ of accidents involving medical products were related to errors by users or usage techniques [18].

To reduce this problem of bad usability, a set of rules has been established for the development of medical products. The International Organization for Standardization (ISO) has established technical and procedural rules on this topic. The Brazilian Association of Technical Standards (ABNT), which is the representative of ISO in Brazil, established several standards related to electromedical equipment. Some of these standards are mandatory requirements for the Brazilian registration of the manufactured product conferred by ANVISA, and others are only recommendations. The international standard IEC 62366 [19] - referring to usability in the medical devices engineering process, which aims to analyze, specify, design, verify and validate the usability of the product that companies produce, in order to minimize the risk of errors caused by usage error - has a national version [20]. This standard is cited by the ABNT NBR IEC 606011-6: 2011 series (referring to usability in electromedical equipment) [21] and its application became mandatory since December 2015 [22]. According to NBR IEC 60601-1-6 and NBR IEC 62366, users can be involved throughout product development to achieve greater usability.

Applying UCD methods throughout the development of medical products can help in the search for good usability. The literature presents many UCD methods, which guide in various ways how to insert the user in a project [23].

However, despite the high number of methods suggested by the literature, it is noted that some aspects of the theory need to be modified. There is, for example, a shortage of specific methods for certain purposes, such as identifying users of a particular product. The "stakeholder map" method helps to identify all the stakeholders of a product, which is extremely important [10], however, more than mapping the stakeholders, the project team must identify the most varied users of their product and have an active involvement with potential users, to collect information about them, such as behavior [24], preferences, skills [25], limitations [26] and needs [27, 28].

It should also be noted that users are one of the groups of stakeholders considered throughout product development [10]. According to the usability standard, the user is the term used for all people who can handle, operate, or otherwise interact with the product. Thus, there may be a wide diversity of these individuals, such as installers, technicians, engineers, doctors, nurses, patients, health professionals in general, cleaning personnel, salespeople, distributors [20], patient caregivers $[29,30]$, elderly patients or even people with disabilities/special needs [30]. Thus, identifying only the stakeholders in a project may not be enough; identifying "user" as a stakeholder is not enough: it is necessary to detail who these users are.

In this context, this work aims to develop a method to identify users of medical products, helping the development team to identify the most varied users of their product, selecting potential users for involvement, and identifying their diverse needs.

\section{Users identification in product development}

Since new product concepts must be based on users' requirements [10], it is essential to know who they are in product development. In the literature, an application trend is the identification of project stakeholders. A stakeholder is any person, group of people, or organization that is affected, directly or indirectly, by the system being developed [31], such as managers, external and internal customers, end-users, consultants, engineers [32], suppliers, resellers [33], installers [34], business owners, government, local communities [35], even the company's production departments [10]. 
At the beginning of every project, the company should create a list of these stakeholders [32]. Such a practice is important because it reminds the project team to consider the diverse needs of everyone who is influenced by the product or service developed [10]. Since it is almost impossible to involve all stakeholders in the product development process [31], it is necessary to prioritize the interests of these stakeholders [36]. To assist in this identification and prioritization, the "stakeholder map" method (also called stakeholder analysis) can be applied. It is a physical representation of the various groups involved in a project [37].

There are different classifications and analysis models that can be used to organize and prioritize stakeholders. They can be classified into primary and secondary [35], strategic and moral [38], classic stakeholder, stakewatchers, and stakeholder [39], according to the stakeholder power and interest level (power vs. interest model) [40] or even according to the potential for threat and potential for cooperation from stakeholders [41]. A very detailed categorization and prioritization of stakeholders is proposed by Mitchell et al. [42], where the stakeholders are classified by attributes of power, legitimacy, and/or urgency in a Venn diagram (called salience model) (Figure 1). With the combination of these three attributes, it is possible to identify eight classes of stakeholders: dormant, discretionary, demanding, dominant, dangerous, dependent, definitive, and nonstakeholder.

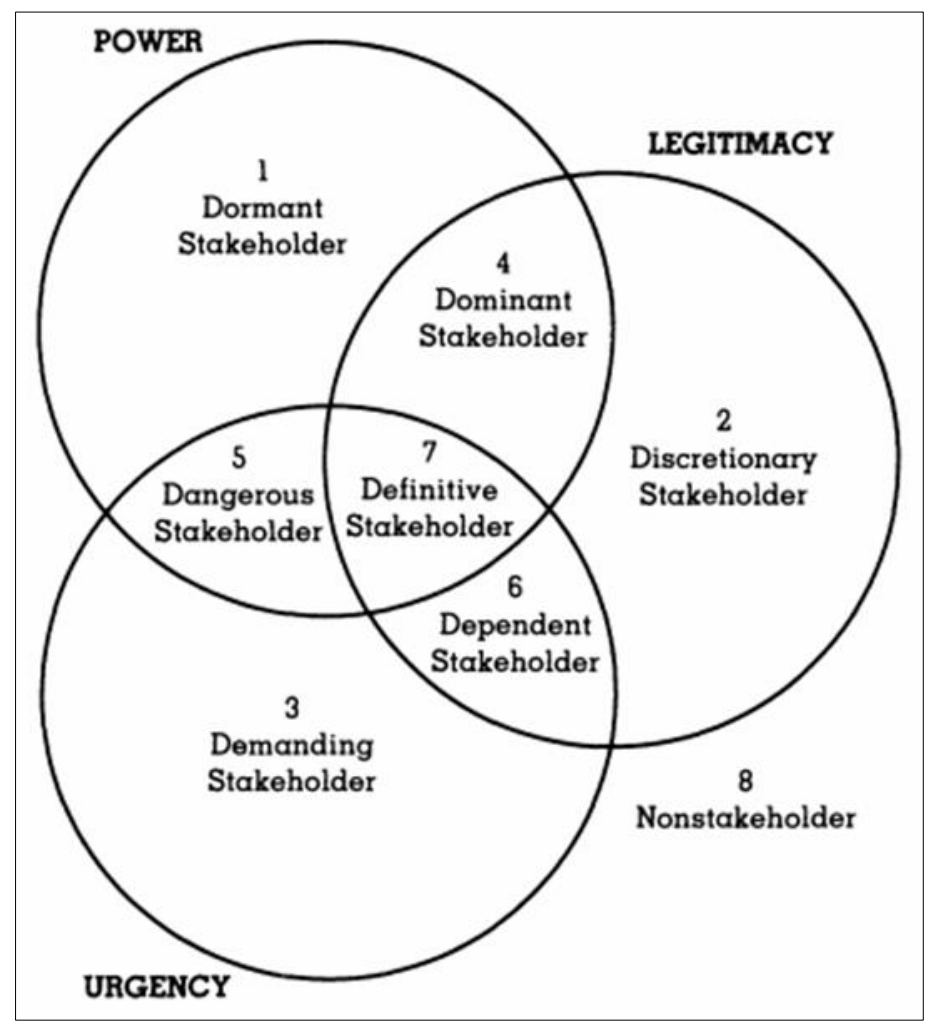

Figure 1 Salience model by Mitchell et al. [42]; (Source: [42])

In addition to these stakeholder classifications, there are several theories of user typologies in the literature, according to their characteristics and consequently with the way they can contribute to a project [43]. Twedt [44] classifies users according to the frequency of purchase or use of a given product: "heavy users" (buy/use the product with high frequency), "light users" (buy/use the product with a median frequency), and "non-users" (do not buy/use the product). For the author, these three types of users are convenient for providing their needs and evaluating product concepts.

Von Hippel [45] classifies users by "lead users", and they are often related to innovative products. Lead users have needs considered as future for other people, that is, that will be desired in the future by other people. This type of user can participate in the generation of concepts [46], providing their needs [45].

In turn, Kristensson et al. [46] group users into: "professional users" (individuals who have high experience using the product), "developer users" (individuals who participate in the product development), "advanced users" (individuals who have knowledge about the use of the product), and "ordinary users" (individuals who do not have professional knowledge about the product). It was identified that the ordinary users generate more original ideas than other users; 
however, such ideas have a low chance of being accomplished since there is a high possibility of technological inconsistency in them. Besides, they can participate in projects to test concepts and also to define the target market [47].

Lettl [43] presents another typology, which has a focus on users of medical products: "inventive users" and "extreme users". According to the author, "inventive users" are doctors who perform modifications or create new product concepts, and they can participate in product development mainly by providing prototypes since they anticipate new technologies in the medical industry. "Extreme users" are doctors who have special needs, and can assist the development team in defining needs more accurately.

It is noted, therefore, that there is a large study in the literature on the identification of stakeholders and user typologies. However, it is clear that there is a gap between these two study themes. Despite its great importance [10], the stakeholders map does not help to identify who are the users of a product (users are considered as one of the stakeholders, but they are not detailed). At the same time, several types of users are studied in the literature. But how to analyze these users and their characteristics, if they have not been identified and detailed? Who are they? Thus, more than mapping stakeholders, it is necessary for the project team to identify the most varied users of your product and have an active involvement with potential users, according to their typology.

\section{Methodology}

The objective of this article is to develop a method for identifying users of medical products. To achieve this goal, three phases were followed, divided into 10 steps, as shown in Figure 2. In the first phase, the first version of the method was elaborated, based on the user's definition and the requirements of the standards engineering process [20,21], and as inspiration the stakeholders map [42]. The method template (a Venn diagram) and an application manual (step 1) were developed. Besides, a questionnaire (Appendix A) was elaborated for those who applied the method to obtain feedback about it (step 2).

Then, the method was applied in a usability workshop on electromedical products, through a focus group (step 3). A total of 16 specialists from the areas of R\&D or certification/quality attended this workshop from 10 companies that develop medical products. The specialists worked in four groups in the development of new products. After applying the Users Broadening Map (UB Map) (which lasted about 50 minutes), all participants answered a questionnaire (step 4). With this feedback, the following changes were made in the method (elaboration of its second version - step 5): improvements in the description of the method categories in its application manual, and an addition of the user's definition in the document.

This second version was used for the last verification of the method (phase 3), which had three case studies in parallel, and in each of them, the proposed method was applied. In the first and second case studies, the UB Map was applied through partnerships between companies and a university: the companies contacted two specialists in product development and ergonomics (authors of this work) and 10 engineering interns. In case study 1, this team worked on a new concept of an inhaler (step 6) and had the participation of three members of the partner company: a quality analyst, the process and production coordinator, and one of the company's partners. In the second case study, the team worked on new product concepts for the city hospital [omitted for blind revision] (step 7), and this project was attended by the hospital's clinical engineering team, whose function is to develop improvements and adaptations in the products used in the hospital. The application of the UB Map lasted approximately 2 hours in each case study.

Also, the UB Map was applied in a company that develops infusion pumps (step 8). Three members of the company applied the method: a certification supervisor, a project manager, and a regulatory manager. The method developers printed the method template for the members of the company, and its application lasted about 1.5 hours. Everyone who applied the method (both the team from case studies 1 and 2 and the members of the company in case study 3 ) answered the same questionnaire (step 9). In addition, members of the companies (from case studies 1 and 2, which followed the application of the method) were interviewed (step 10). With both feedbacks (from questionnaires and interviews), the last version of the method was elaborated (step 11). As a last change in the method, "application location" information in the manual and a more detailed description of the types of users were added. 


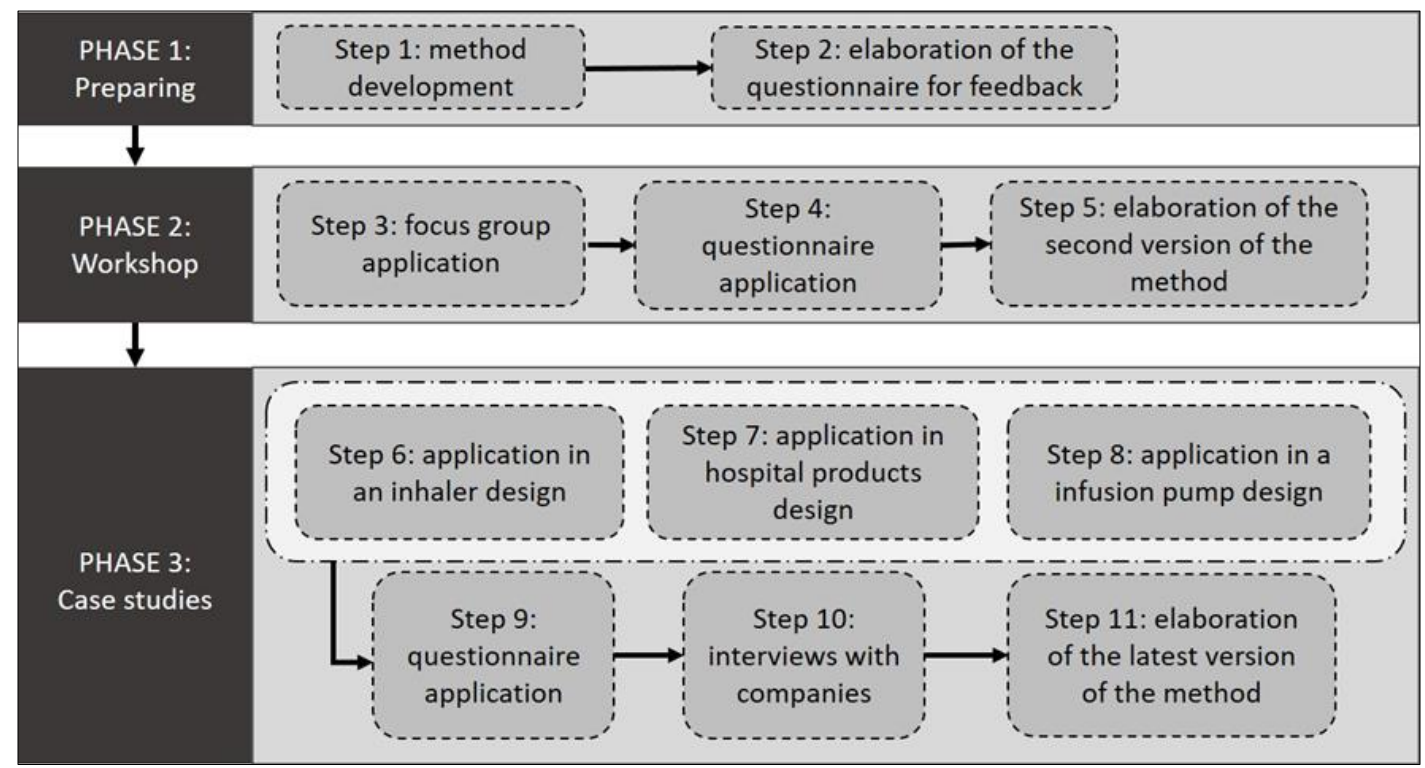

Figure 2 Phases and steps followed in this research

\section{Results}

The results of this work are organized in this section as follows: first, the Users Broadening Map (UB Map) method is presented (its description, template, and step by step application). Then, the results of the applications of the method in the focus group are presented, followed by the results of the applications in the case studies. Still, the benefits that were achieved with the UB Map are discussed and, finally, some identified difficulties are mentioned.

\subsection{The Users Broadening Map (UB Map)}

The Users Broadening Map (UB Map) is a method that helps the project team to identify a large number of users of the product that is being developed. This identification is important to ensure that the needs of all users are addressed since different users have different limitations, skills, and needs.

The method consists of a three-category Venn diagram (template in

Figure 3): operational use, technical use, and other uses. The "operational use" category includes users who are interested in operational aspects of the product (who have direct contact and make direct use of the product). In general, these users are the ones who actually use, handle, or interact with the product, e.g. nursing technicians, caregivers, etc. It is important to point out that the handling of the product in its packaging should not be considered as handling the product itself, since that user only handles the box (in this case, the user would be classified in the "other uses" category).

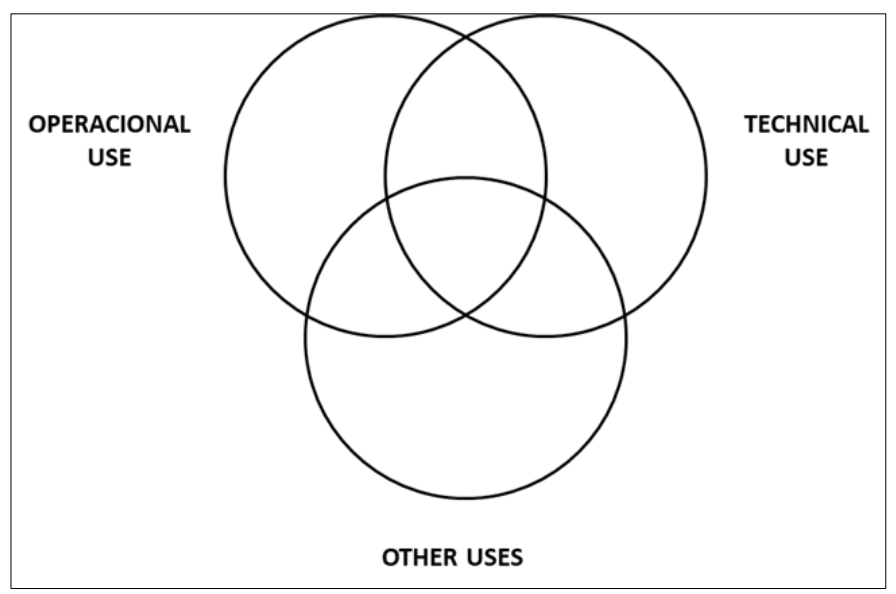


Figure 3 The UB Map template

The "technical use" category contains users who are interested in technical aspects of the product (e.g. how it should work, what functional characteristics it should have). In general, these users have technical knowledge of the product and/or use the result generated from the product. Some examples of these users are doctors, those responsible for maintenance, disposal, etc. Finally, the category of "other uses" covers users who have different interests, who do not necessarily handle the product for their use, as responsible for sales, transportation (personal or business), responsible for reverse logistics, etc.

\subsubsection{How to apply the UB Map}

To apply the UB Map, it is necessary to have at least three members of the company (at least one of them from the project team), and that they all have pens and sticky notes available. For the application, the participants do not need to be in any specific location. The application lasts between one to two hours.

First, the team needs to have the physical form template available (printed or hand-drawn), preferably in a size equal to an A3 sheet or larger. Then, the project team must follow the following steps:

Step 1. All users of the product that is being developed must be considered. In this step, the development team brainstorms users, using sticky notes. Each participant must brainstorm individually, writing as many users as he/she can identify, each one on a sticky note. For the users' identification, it is important to pay attention to the definition of the standard:

"User is the term commonly used in professional usability engineering activity for any humans who can handle, operate, or otherwise interact with the product. There can be a wide diversity of these individuals for any particular product, including: installers, engineers, technicians, doctors, patients, healthcare professionals, cleaning staff, salespeople and distributors, etc." (translated by the authors from [20, p.18]).

To help identify users, participants can ask themselves:

- Who are the end-users of the product?

- How is the end user's day to day? Who does he/she have contact with in the environments he/she frequents?

- Are end-users dependent on someone?

- Who prescribes the use of the product?

- Who decides on the purchase limit for the product?

- Is there product maintenance (cleaning, replacement of parts, lubrication, replacement of batteries, etc.)? Who does it?

- Who has contact with the product in general?

- Does the disposal of waste of this product require any specific process or procedure? Who does it?

- How is this product stored? Does it require any specific procedure? Who does it?

- Where / how is it sold?

Step 2. After identifying the users, it is necessary to reflect on whether they need to be segmented or regrouped. When in doubt, the team should ask itself if, among these users, there is a subset that would make a different use with the product, or even if there is a subset that would have different needs from others. If so, the team must segment the user. For example, the user "children", segmented into "children up to 3 years old", "children aged 4 to 6 years old", and "children aged 7 to 10 years old".

Step 3. With the identified users, it is necessary to organize them in the method template (

Figure 3) according to the category (s) of users in which they fall. The sticky notes should be organized in groups (not individually as in step 1).

Step 4. After organizing the users, it is necessary to select the users that the development team will prioritize to interview and collect their needs. Preferably, the team should prioritize users at template intersections, so it is possible to raise needs from more than one user point of view. In addition, it should try to diversify the chosen users between the categories of the template. 


\subsection{UB Map application in the focus group}

A total of 16 specialists (from R\&D and certification areas) attended the workshop. They come from 10 companies that develop medical products. There was a great diversification of companies, both in areas of developed products and in age, as can be seen in Table 1.

Table 1 Details of the companies that participated in the focus group

\begin{tabular}{|c|l|c|c|}
\hline Company & \multicolumn{1}{|c|}{ Produced product areas } & $\begin{array}{c}\text { Foundation } \\
\text { year }\end{array}$ & $\begin{array}{c}\text { Number of } \\
\text { participants }\end{array}$ \\
\hline A & $\begin{array}{l}\text { Odontology, medical clinic, and aesthetics (office and surgery } \\
\text { purposes) }\end{array}$ & 1998 \\
\hline B & Ophthalmology (diagnostic purposes) & 1992 & 1 \\
\hline C & $\begin{array}{l}\text { Ophthalmology, gynecology, and otolaryngology (office, } \\
\text { diagnostic, and surgery purposes) }\end{array}$ & 1999 & 2 \\
\hline D & $\begin{array}{l}\text { Dermatology for aesthetic, vascular, and plastic surgery (office } \\
\text { and surgery purposes) }\end{array}$ & 2015 & 3 \\
\hline E & $\begin{array}{l}\text { Ophthalmology and medical clinic (office, diagnostic, and surgery } \\
\text { purposes) }\end{array}$ & 2015 & 2 \\
\hline F & Neurology (surgery purposes) & 2014 & 2 \\
\hline G & $\begin{array}{l}\text { Neonatology, gynecology, dermatology, ophthalmology, } \\
\text { otolaryngology, medical/hospital clinic (office, diagnostic, and } \\
\text { surgery purposes) }\end{array}$ & 1988 & 1 \\
\hline H & $\begin{array}{l}\text { Cardiology and medical/hospital clinic (diagnostic and surgery } \\
\text { purposes) }\end{array}$ & 1985 & 1 \\
\hline I & Cardiology and pulmonology (diagnostic and surgery purposes) & 1950 & 1 \\
\hline J & Phototherapy (aesthetics and treatment purposes) & 2014 & 2 \\
\hline
\end{tabular}

The 16 participants were divided into four groups, with no group remaining with members of only one type of specialization. It was presented to them that they would work on a redesign project for inhalers (chosen so that none of the companies developed such a product, promoting no advantage to any of the participants), and after they became familiar with the theme, the UB Map was applied (Figure 4). 


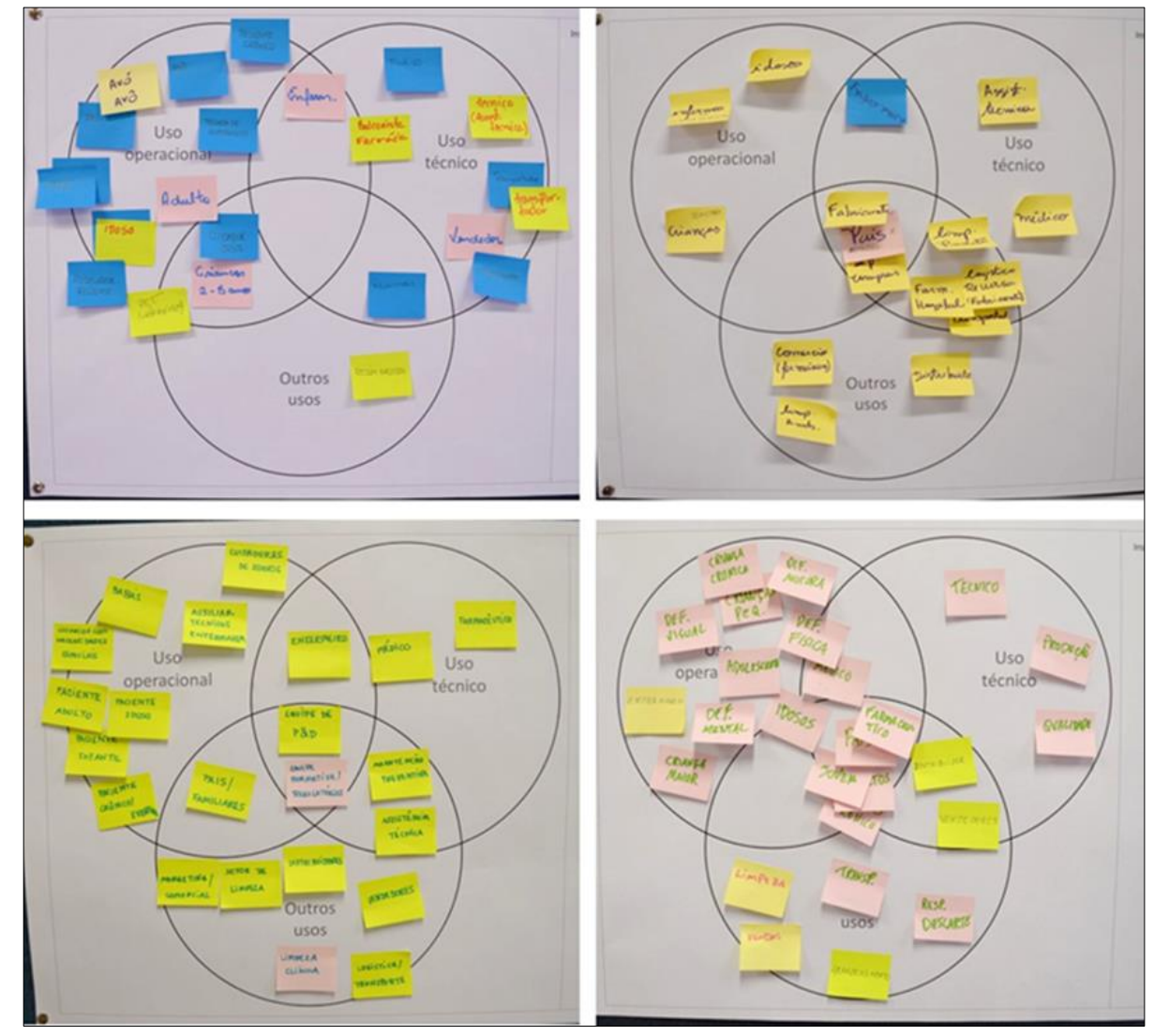

Figure 4 UB Map templates from the four groups

\subsection{UB Map application in the case studies}

The partner company of the first case study where the UB Map was applied was founded in 1978 as a service provider in the hospital area. Currently, it manufactures and imports products from exclusive lines of medical products, such as inhalers, aspirators, blood pressure meters, ophthalmoscopes (veterinary line), among many others. Its products are destined for the entire national territory. The project to which the UB Map was applied was residential compressed inhalers (Figure 5). The company needed a new design and new features to stand out in the market, but it was required to maintain a low-cost product to continue with the target audience of lower-income. 


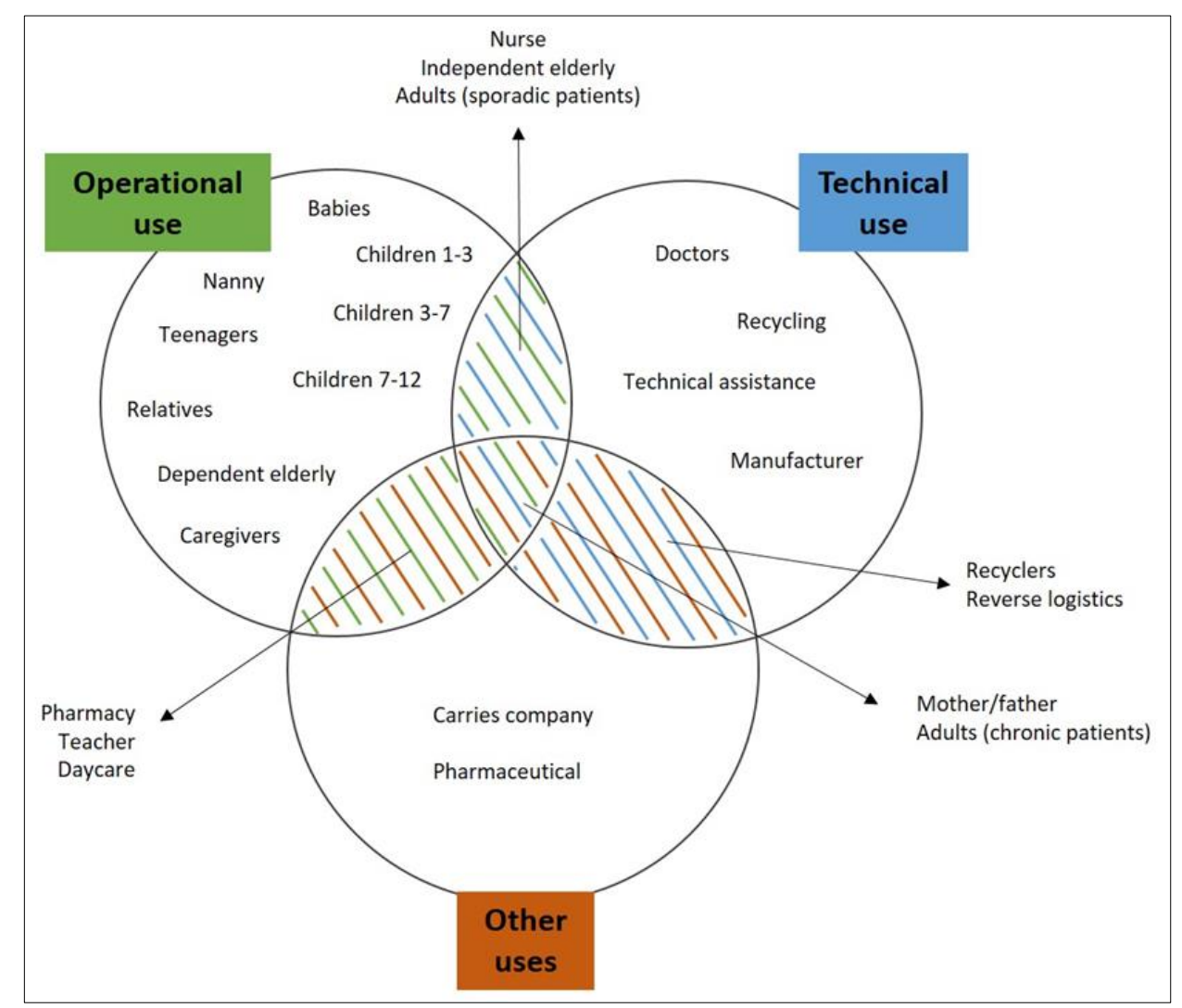

Figure 5 UB Map elaborated in case study 1

The second case study was applied in partnership with a hospital in the same municipality as the university. Founded in 1891, it is the oldest working, charitable, and hospital institution operating in the city. Attends private health insurance patients or those coming from the public health system.

A large part of the products used in the hospital (for non-medical use) needed updates, whether for the sake of patient comfort or safety, practicality for nurses, the addition of features, or even aesthetics. Thus, they sought a partnership with the university so that new projects could be developed. The hospital gave the challenge of redesigning the following products: stretchers, food transport trays, and wheelchairs.

The third case study took place in a company that developed hospital infusion systems. Founded in 1987, it has a complete line of equipment composed of syringe pumps, rotary and linear volumetric pumps, in addition to a vast line of equipment. The company was undergoing an innovation process in its infusion pump business model, and for that, it was essential to identify the users of such products. Thus, the UB Map was applied (Figure 6) for a new business model for infusion pumps. Error! Reference source not found. presents the method template filled in by the company members. 


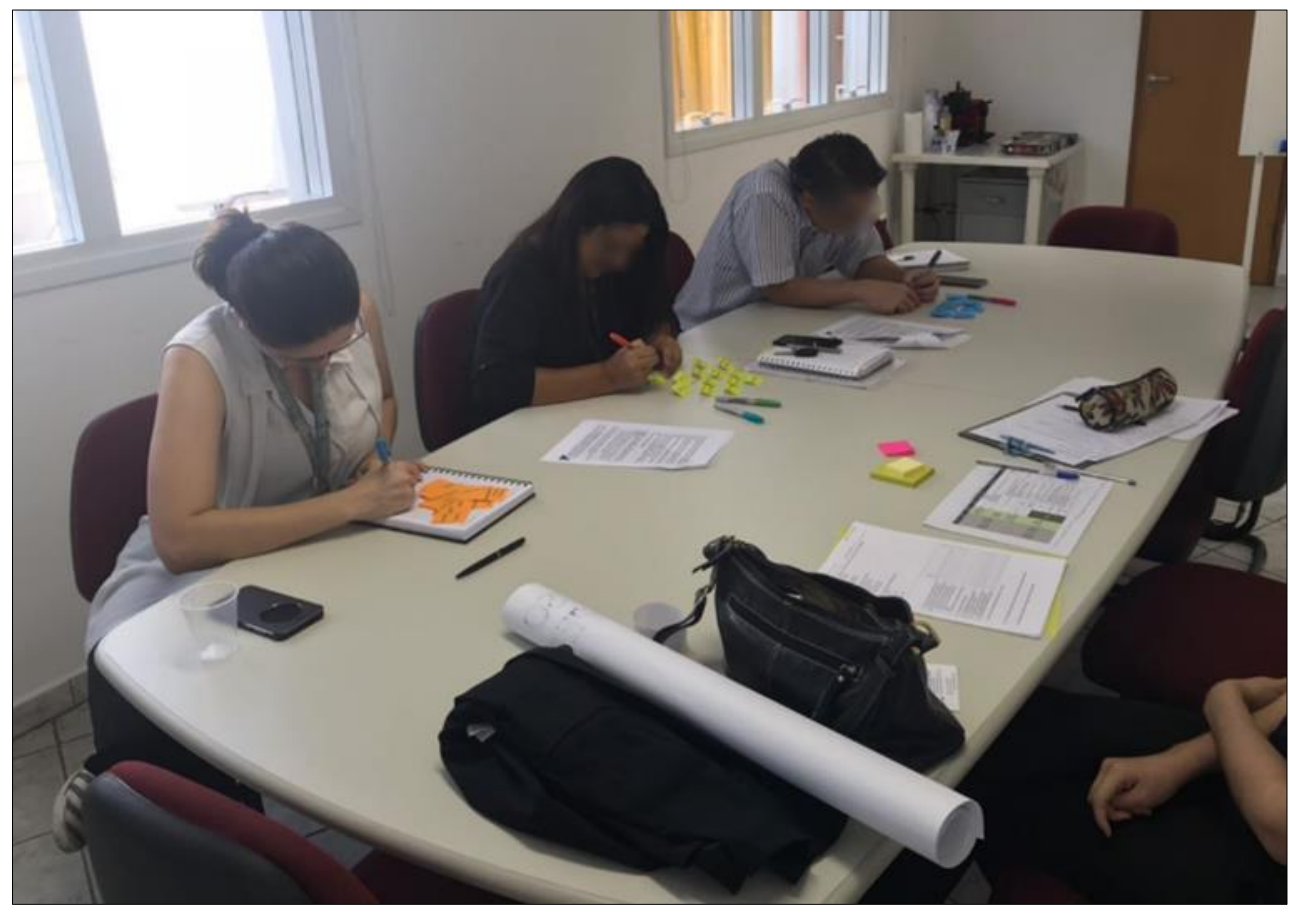

Figure 6 Participants in the third case study, brainstorming users

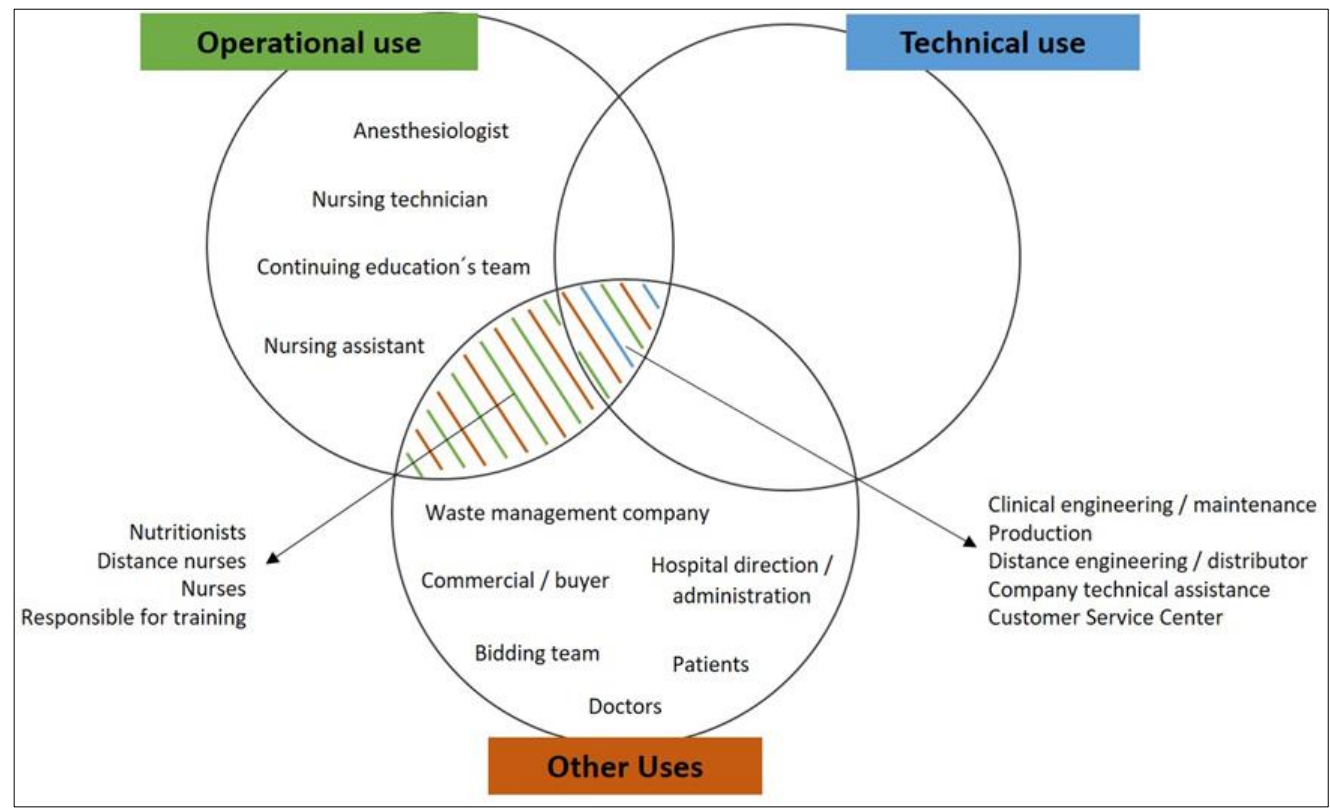

Figure 7 UB Map elaborated in case study 3

\subsection{Benefits achieved}

After the method application in the case studies, with the analysis of the responses to the questionnaires and also of the interviews carried out, it was possible to identify many benefits achieved by applying the UB Map.

\subsubsection{A better understanding of the user definition of the standard}

The ABNT NBR IEC 62366 standard [20] presents a definition of what is considered a user of medical products. Despite this, throughout the workshop, all members of the companies claimed not to remember this definition, and even with its resumption, many still had difficulty in understanding it. After the presentation of the method, the reading of its step 
by step and its application, the participants stated that the UB Map contributes to a better understanding of users of medical products, consequently, a better identification of users.

\subsubsection{A higher number of identified users}

Before applying the method, in all the case studies and in the focus group carried out, it was asked whom the participants believed to be the users of the analyzed products. After applying the method, it was possible to observe that in all cases there was a significant increase in the number of users identified.

In the first case study, team members previously identified only three users of inhalers (children, the elderly, and adults). In the focus group carried out (also to bring improvements to inhalers), the participants identified only two users (nurses and parents). With the method, both the team and the workshop participants identified 25 users each, but with some differences. Commonly identified users were manufacturer, doctors, relatives, mother/father, babies, nurse, caregiver, nanny, pharmaceutical, pharmacy / seller, adults (sporadic patients), adults (chronic patients), technical assistance, and carries company. In both cases, "children" was identified as a user, but with different segmentations (the team has identified: children 1-3 years old, children 3-7, children 7-12; and the company participants have identified: children 1-2, children 3-5, and children 6-9). The participants identified the user "elderly" but did not segment as the team did (dependent elderly, independent elderly). Besides, the team identified the following users: teenagers, recycling companies, recyclers, reverse logistics' team, teacher, and daycares. In contrast, the users identified only by the participants in the workshop were nursing technicians, patients with special needs, veterinarian, responsible for marketing/commercial, hospital cleaning sector, R\&D team, normative/regulatory team.

In the second case study, the team worked on three projects (stretchers, food trays, and wheelchairs). In the stretcher project, two users were initially identified (nurses and patients), and after the method application, this number increased to 9 (nurses, adult patients, child patients, elderly patients, doctors, makeup artists, maintenance staff, hospital management team) hospital, operating room staff). Users of food transport trays were from two (nurses, patients) to 7 (nurses, adult / elderly patient with food restriction, adult / elderly patient without food restriction, child patient with food restriction, child patient without food restriction, team cleaning staff, nutritionists), and wheelchair users, from 5 (adult, child, obese, nurses, caregivers) to 11 (additionally: hospital cleaning staff, technical assistance, family members, physiotherapist, doctor, manufacturer).

In the third case study (infusion pumps), five users were initially identified (auxiliary and nursing technician, doctor, clinical engineer, clinic). After the UB Map application, 19 users of the pump were identified by the participants: nursing assistant, anesthesiologist, nursing technician, continuing education team, nutritionist, nurse STR / dist., Responsible for standardization (who trains), clinical engineering/maintenance, production, engineering distributor, company technical assistance, customer service, nurse, bidding team, general practitioners, patient, commercial/buyer, hospital management/administration, waste management company.

All participants in the focus group recognized that correctly identifying all users of an electromedical product is very important, because, by understanding who these users are, it is possible to identify their needs, designing products aimed at users and with good usability.

\subsubsection{Segmenting user groups}

With the help of the step-by-step method, the participants were able to notice that some groups of users needed to be separated into two or more users. For example, in the inhaler project (case study 1 and focus group), the team and members of the companies realized that having a group of "children" could make the development team forget about some specific needs of younger children or even older children. The same occurred with the "adults" group, where adults with some chronic respiratory disease, who use the inhaler daily, may have different needs than adults who use the product sporadically; then some with "elderly people", where independent elderly people may have different needs than dependent elderly people. Thus, the participants listed specific users and not in a generic way.

Therefore, paying attention to different segments of users is important for a broader identification of different needs. Identifying these different needs can add more value to the product, and the company may have a differential in the market. 


\subsubsection{Guidance for prioritizing user requirements}

After the application of the method, the participants of case study 3 observed that the UB Map can also contribute to the prioritization of requirements in later stages of product development. With the identification of the users and their role in the project, the project team has a justification and an orientation of which user and consequently which requirements to prioritize. Having a prioritization of requirements is essential because, in most cases, requirements are in conflict with each other and trade-offs are necessary [48].

\subsubsection{Guidance for selecting potential users for tests}

The representatives of the case study company 1 and the participants of case study 3 stated that with the results of the UB Map it is possible to have an orientation of which users to select to make concept tests, prototypes, or even final product. Once you have a feature coming from a specific need, it is essential to test that feature with the user who has that need. Another observation reported was that it is possible to make a selection of users who can perform multitests, which would save time and resources for the company, and still, it would not lack the necessary feedbacks.

\subsection{Difficulties identified}

The focus group participants encountered some difficulties when applying the method. One of the difficulties was the difference between a technical user and an operational user. Therefore, the definition of the types of users in the method step by step has been improved, and it is believed that this difficulty is minimized with the practice of the method.

Furthermore, although all 16 focus group participants agreed that applying this method would benefit their companies, they cited some possible barriers to its application, which are:

- Breaking paradigm and business culture: the method can be seen initially as a waste of time;

- R\&D team: gathering the team to apply the method can be a barrier, as well as having an adequate number of people on the team to generate a good brainstorming of users and having these people trained to have this look;

- Lack of knowledge of the members of the company: the lack of elaborated concepts about usability can make the team members not believe in the results of the method

\section{Conclusion}

Due to a scarcity of methods to raise users of a given product, the Users Broadening Map (UB Map) was developed, having as its inspiration the salience model [42]. The UB Map consists of a Venn diagram with categories and descriptions based on the user definitions and usability engineering process of ABNT NBR IEC 60601-1-6 and 62366 standards [21].

The development of this method aimed to guide companies that develop medical products to survey of the most varied users of a product, to help the development team to identify which different users with whom they may have contact during the development of products. UB Map is a template with three categories of users: operational use (users who are interested in operational aspects of the product, with direct contact and direct use of the product), technical use (users who are interested in technical aspects of the product, e.g. how it should work, what functional characteristics it should have), and other uses (users who have diverse interests, who do not necessarily handle the product for its use).

Many benefits have been identified with the application of the UB Map. It brings a better understanding of what a user is to the development team and facilitates the identification of different users, which is essential in the reporting for usability certifications $[20,21]$. Still, the method can help in prioritizing requirements and in selecting potential users for testing concepts, prototypes, and products. With the method, the project team also fragments large groups of users, which contributes to a more in-depth identification of needs.

In addition to the template, the material developed in this work has a step by step application. All participants in the focus group were satisfied with the explanation of the method, its description, and the information contained in the step by step. The categories created were also praised. It was also praised that they were able to have a justification for whom to look for information and a justification of which requirement / which user to prioritize. Another aspect mentioned was that the information obtained with the method can be used for other future projects and certification reports. 
Our suggestion is that the UB Map be applied by companies at the beginning of the development of new medical products, or even in product redesign. By identifying as many users as possible and seeking to involve such users in product development, companies can achieve greater usability in their products, reducing risks and misuse of them. In addition, the result of the method can be used in the preparation of reports for certification.

\section{Compliance with ethical standards}

\section{Acknowledgments}

The authors cordially thank the Coordination of Improvement of Higher Education Personnel (CAPES) for supporting this research.

\section{Disclosure of conflict of interest}

The authors declares that there is no conflict of interest in their research study.

\section{References}

[1] L Rochford, W Rudelius. New Product Development Process, Ind. Mark. Manag. 1997; 26, pp. 67-84, 1997.

[2] J Maldonado. Documento setorial: Equipamentos Médicos. Projeto: Perspectivas do Investimento no Brasil (PIB). Bloco: Economia do Conhecimento. Sistema Produtivo: Complexo Industrial da Saúde. UFRJ e UNICAMP. 2009.

[3] L Wood. Global Medical Devices Market Report 2019-2022 - A \$521+ Billion Opportunity Analysis, Globe News Wire. Reasearch and Markets, 2019. Available at: <https://www.globenewswire.com/newsrelease/2019/09/19/1918062/0/en/Global-Medical-Devices-Market-Report-2019-2022-A-521-BillionOpportunity-Analysis.html>. Accessed on 18 August 2020.

[4] ABIMO. "Dados do comércio exterior." 2018. Available at: <https://abimo.org.br/dados-do-setor/dados-decomercio-exterior/>. Accessed on 15 February 2019.

[5] Informa Markets. Crescimento do setor de dispositivos médicos foi de 13,5\% em 2018, Saúde Business, 2019. Available at: <https://saudebusiness.com/mercado/crescimento-do-setor-de-dispositivos-medicos-foi-de-135em-2018/>. Accessed on 18 August 2020.

[6] FJ De Ana, KA Umstead, GJ Phillips, CP Conner. Value driven innovation in medical device design: A process for balancing stakeholder voices, Ann. Biomed. Eng. 2013; 41(9): 1811-1821.

[7] H Rozenfeld et al. Gestão de Projetos em Desenvolvimento de Produtos. São Paulo: Saraiva.2006.

[8] RG Cooper. Winning at New Products: Accelerating the Process from Idea to Launch, 3th. Perseus Publishing. 2001.

[9] MB Privitera, M Evans, D Southee. Human factors in the design of medical devices - Approaches to meeting international standards in the European Union and USA, Appl. Ergon. 2017; 59: 251-263.

[10] KT Ulrich, SD Eppinger. Product Design and Development, 5th ed. McGraw-Hill Irwin. 2012.

[11] C Campese, DC Amaral, J Mascarenhas. Restating the Meaning of UCD and HCD for A New World of Design Theories, Interact. Comput. 2020; 32(1).

[12] J Karat. User Centered Design: quality or quackery?, Mag. Interact. 1996; 10(4): 18-20.

[13] S Barrington. Usability in the Lab: Techniques for Creating Usable Products, JALA - J. Assoc. Lab. Autom. 2007; 12(1): 6-11.

[14] J Nielsen. Usability Engineering, vol. 44. Academic Press. 1993.

[15] International Organization for Standardization, "ISO 9241-11. Ergonomic requirements for office work with visual terminals (VDTs) - Part 11: guidance on usability." 1998.

[16] J Zhang, TR Johnson, VL Patel, DL Paige, T Kubose. Using usability heuristics to evaluate patient safety of medical devices, J. Biomed. Inform. 2003; 36(1-2): 23-30. 
[17] LSA Rezende, M Bernardes, CHP Mello. Engenharia da usabilidade aplicada ao desenvolvimento de equipamentos médicos: uma revisão sistemática, in 10o Congresso Brasileiro de Gestão da Inovação e Desenvolvimento de Produtos. 2015; 1-10.

[18] ECRI Institute. Executive brief. Top 10 Health Technology Hazards for 2016, no. November 2015. 2016.

[19] E. IEC. 62366, Medical Devices-Application of Usability Engineering To Medical Devices, 2008.

[20] Associação Brasileira de Normas Técnicas. ABNT NBR IEC 62366. Produtos para a saúde — Aplicação da engenharia de usabilidade a produtos para a saúde. Rio de Janeiro. 2016.

[21] Associação Brasileira de Normas Técnicas. ABNT NBR IEC 60601-1-6. Equipamento eletromédico Parte 1-6: requisitos gerais para segurança básica e desempenho essencial - norma colateral: usabilidade. 2013.

[22] Brasil. Ministério da Saúde. Agência Nacional de Vigilância Sanitária (ANVISA). Normative Instruction Number 4, 24 September 2015.

[23] C Campese, JL Scatolin, RFS Esposto, JMH da Costa. Estudo dos métodos de UCD, in 10 o Congresso Brasileiro de Gestão da Inovação e Desenvolvimento de Produtos. 2015; 1-12.

[24] B. Göransson. Usability Design : A Framework for Designing Usable Interactive Systems in Practice, Uppsala University. 2001.

[25] R Wever, J van Kujik, C Boks. User-centred design for sustainable behaviour, Int. J. Sustain. Eng. 2008; 1(1): 9-20.

[26] M Haklay, C Tobón. Usability Evaluation and PPGIS: towards a user- centred design approach," Int. J. Geogr. Inf. Sci. 2003; 17(6): 577-592.

[27] C Abras, D Maloney-Krichmar, J Preece. User-centered design, Bainbridge, W. Encycl. Human-Computer Interact. Thousand Oaks Sage Publ. 2004; 37(4): 445-456.

[28] G Randolph. Use-cases and personas: A case study in light-weight user interaction design for small development projects, Informing Sci. 2004; 7: 105-116.

[29] JL Martin, B Norris, E Murphy, J Crowe. Design for patient safety. User testing in the development of medical devices. National Patient Satefy Agency, London. 2010; 68.

[30] SGS Shah, I Robinson, S AlShawi. Developing medical device technologies from users' perspectives: A theoretical framework for involving users in the development process, Int. J. Technol. Assess. Health Care. 2009; 25(4): 514521.

[31] I Sommerville. Engenharia de Software, 8a. edição. São Paulo: Pearson Addison-Wesley. 2007.

[32] RS Pressman. Software Engineering. A practitioner's approach, 7th ed. New York: McGraw-Hill. 2010.

[33] CM Crawford, CA Di Benedetto. The New products Management, 10th ed. McGraw-Hill. 2010.

[34] M Maguire. Methods to support human-centred design, Int. J. Hum. Comput. Stud. 2001; 55(4): 587-634.

[35] RE Freeman. Strategic management: A stakeholder approach. 1984; 1.

[36] J McManus. A stakeholder perspective within software engineering projects, Eng. Manag. Conf. 2004. Proceedings. 2004 IEEE Int. 2004; 2: 880-884.

[37] M Stickdorn, et al. This is service design thinking. Basics - Tools - Cases. Amsterdam: BIS Publishers. 2011.

[38] K. E. Goodpaster, "Business ethics and stakeholder theory,” Corp. Soc. Responsib. 2017; 145-174.

[39] Y Fassin. Working Paper the Stakeholder Model Refined, J. Bus. 2008; 1-46.

[40] AL Mendelow. Environmental Scanning - the Impact of the Stakeholder Concept., Proc. Int. Conf. Inf. Syst. 1981; 407-417.

[41] GT Savage, TW Nix, D Blair, GTN Savage Timothy W. Whitehead, Carlson J Blair, John D. Strategies for assessing and managing organizational stakeholders., Acad. Manag. Exec. 1991; 5(2): 61-75.

[42] RK Mitchell, BR Agle, DJ Wood. Toward a theory of stakeholder identification and salience: Defining the principle of who and what really counts, Acad. Manag. Rev. 1997; 22(4): 853-886.

[43] C Lettl. User involvement competence for radical innovation, J. Eng. Technol. Manag. - JET-M. 2007; 24(1-2): 5375 . 
[44] DW Twedt. How important to marketing strategy is the 'Heavy User'?," J. Mark. 1964; 28(1): 71-73.

[45] E von Hippel. Lead Users: a Source of Novel Product Concepts.," Manage. Sci. 1986; 32(7): 791-805.

[46] P Kristensson, A Gustafsson, T Archer. Harnessing the Creative Potential among Users, J. Prod. Innov. Manag. 2004; 21(1): 4-14.

[47] MA Kaulio. Customer, consumer and user involvement in product development: A framework and a review of of selected methods, Total Qual. Manag. 1998; 9(1): 141-149.

[48] J Jiao, MM Tseng. A requirement management database system for product definition, Integr. Manuf. Syst. 1999; 10: $146-154$.

\section{Appendix A. Questionnaire for UB Map feedback.}

Name: Formation / university graduate:

Company: Position in the company:

1. The description of the categories in the method manual was sufficient for its understanding.

() I totally agree

() I partially agree

() Indifferent

() I partially disagree

( ) I totally disagree

2. The purpose of the method was clear.

() I totally agree

() I partially agree

() Indifferent

() I partially disagree

( ) I totally disagree

3. How was it to distinguish one category from the other?

( ) Very easy

( ) Easy

() Indifferent

() Hard

( ) Very hard

\begin{tabular}{|c|c|c|c|c|c|c|c|c|c|c|}
\hline & \multicolumn{10}{|c|}{ 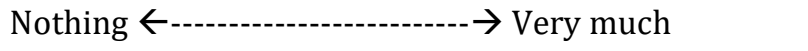 } \\
\hline & 1 & 2 & 3 & 4 & 5 & 6 & 7 & 8 & 9 & 10 \\
\hline $\begin{array}{l}\text { 4. How much did the method contril } \\
\text { identification of users of the produc }\end{array}$ & & & & & & & & & & \\
\hline $\begin{array}{l}\text { 5. How much do you think this } \mathrm{n} \\
\text { contribute to a better ideas organiz }\end{array}$ & & & & & & & & & & \\
\hline 6. And to maintain the project's focus c & & & & & & & & & & \\
\hline 7. And to generate new concepts? & & & & & & & & & & \\
\hline 8. And to identify user requirements? & & & & & & & & & & \\
\hline
\end{tabular}


World Journal of Advanced Engineering Technology and Sciences, 2021, 03(02), 050-064

\begin{tabular}{|l|l|l|l|l|l|l|l|l|l|l|l|}
\hline 9. And to prioritize requirements? & & & & & & & \\
\hline $\begin{array}{l}\text { 10. And to select potential users for } \\
\text { concept/prototype/product tests? }\end{array}$ & & & & & & & & & & \\
\hline
\end{tabular}

11. What was the biggest difficulty you had applying the method?

12. Can you identify any other aspect of the method, not listed in this questionnaire?

13. Do you have any suggestions for modifications or improvements? 